\title{
A new X-ray-transparent flow-through reaction cell for a $\mu$-CT-based concomitant surveillance of the reaction progress of hydrothermal mineral-fluid interactions
}

\author{
Wolf-Achim Kahl ${ }^{1}$, Christian Hansen ${ }^{1, a}$, and Wolfgang Bach ${ }^{1,2}$ \\ ${ }^{1}$ Department of Geosciences, University of Bremen, Klagenfurter Straße (GEO), 28359 Bremen, Germany \\ ${ }^{2}$ MARUM, Center for Marine Environmental Sciences, 28359 Bremen, Germany \\ ${ }^{a}$ now at: Research Group for Marine Geochemistry (ICBM-MPI Bridging Group), Carl von Ossietzky University of \\ Oldenburg, Institute for Chemistry and Biology of the Marine Environment (ICBM), 26129 Oldenburg, Germany
}

Correspondence to: Wolf-Achim Kahl (wakahl@uni-bremen.de)

Received: 2 February 2016 - Published in Solid Earth Discuss.: 3 February 2016

Revised: 11 April 2016 - Accepted: 12 April 2016 - Published: 22 April 2016

\begin{abstract}
A new flow-through reaction cell consisting of an X-ray-transparent semicrystalline thermoplastic has been developed for percolation experiments. Core holder, tubing and all confining parts are constructed using PEEK (polyetheretherketone) to allow concomitant surveillance of the reaction progress by X-ray microtomography $(\mu-\mathrm{CT})$. With this cell setup, corrosive or oversaturated fluids can be forced through rock cores (up to $\varnothing 19 \mathrm{~mm}$ ) or powders at pressures up to $100 \mathrm{bar}$ and temperatures up to $200^{\circ} \mathrm{C}$. The reaction progress of the experiment can be monitored without dismantling the sample from the core holder.

The combination of this flow-through reaction cell setup with a laboratory X-ray $\mu$-CT system facilitates on-demand monitoring of the reaction progress of (long-term) hydrothermal experiments in the own laboratory, keeping interruption times as short as possible. To demonstrate both the suitability of the cell construction material for X-ray imaging purposes and the experimental performance of the flow-through system, we report the virtually non-existent bias of the PEEK cell setup with distinctive X-ray observations (e.g., differing states of pore fillings: air vs. fluid; detection of delicate fabric elements: filigree zeolite crystals overgrowing weathered muscovite), and the monitoring of the gypsum/anhydrite transition as a case study of a 4-D fabric evolution.
\end{abstract}

\section{Introduction}

Fluid-rock interactions govern the critical mass transfers involved in the exchange between the oceanic crust and seawater and the formation of hydrothermal deposits in a range of settings. They also influence hydraulic and rock mechanical properties and are hence relevant to applied geosciences. Understanding these processes requires consideration of multiple factors, including changes in porosity distribution, permeability and their relationship with critical dissolution and precipitation rates. To date, the knowledge of these interdependencies is very limited, and we are hence often unable to make reliable predictions of fluid-rock behaviour in natural systems.

In numerical simulations of hydrothermal systems, fluid flow, heat- and matter transport, and chemical reaction progress have to be considered simultaneously (e.g., Kühn, 2009). The first step in understanding macroscopic rock properties, such as permeability or capillary pressure, is the correlation of rock microstructure and physical properties of the fluid at the pore-scale. A crucial part in this is the transformation of real pore space geometries into appropriate pore space models. In this regard, true 3-D spatially resolved spectroscopic data (e.g., nuclear magnetic resonance; laboratorybased and synchrotron-based computed microtomography: $\mu$-CT) is superior to pure statistical considerations of porous media, e.g. by mercury porosimetry (Øren and Bakke, 2003). Recent studies demonstrated that structural heterogeneities on the pore-scale in rocks govern the hydrodynamic flow 
zones within porous media. In turn, these hydrodynamic flow zones control transport and reaction processes and local and effective reaction rates (e.g., Andreani et al., 2009). Suitably, $\mathrm{X}$-ray microtomography facilitates the non-invasive assessment of microfabrics in the $\mu \mathrm{m}$-range. The non-destructive nature of $\mu$-CT investigations is of paramount importance for monitoring reaction progress in long-term fluid-rock reaction experiments. Several studies have successfully employed $\mu$-CT-derived pore space geometries and experimental data from percolation experiments with rock microcores to parametrize coupled transport-reaction models (e.g., Flukiger and Bernhard, 2009; Noiriel et al., 2009).

In a number of studies, reaction progress in hydrothermal fluid-rock interaction experiments was investigated by means of lab-based or synchrotron $\mu$-CT: pore space evolution, changes in rock fabric and mineral surface area, as well as hydraulic scale displacement effects in percolation experiments were quantified by comparison of the initial and the post-reaction states. This procedure has been applied to a variety of geological materials and model rock analogues of various dimensions, e.g. micro-cores of sandstone (Sell et al., 2013: core $\varnothing 47.6 \mathrm{~mm}$, length $46.0 \mathrm{~mm}$ ), limestone (Gouze and Luquot, 2011: core $\varnothing 9 \mathrm{~mm}, 18 \mathrm{~mm}$ length; Smith et al., 2013a: core $\varnothing 15 \mathrm{~mm}, 30 \mathrm{~mm}$ length; Vialle et al., 2014: $\varnothing 100 \mathrm{~mm}$, length $350 \mathrm{~mm}$ ), anhydrite (Smith et al., 2013b: core length $30 \mathrm{~mm}$ ), limestone analogue (Noiriel et al., 2012: mixed calcite grains and glass beads, $\varnothing 6.5 \mathrm{~mm}$, length $12 \mathrm{~mm}$ ).

All former studies have in common, however, that the samples were only scanned twice, prior to confinement within the reaction cell and at the end of the experiments after a complete dismantling. Reaction concomitant scans were not possible, either because non-transparent X-ray reactor materials were used or because of impracticabilities in introducing the pressure housing into the beam chamber. In case of 4-D $\mu$-CT studies that rely on more than the initial and the final time step, removing the sample from the experiment, and its reassembly after scan, has to be mastered with minimal perturbation of the core. Burlion et al. (2006) performed leaching experiments on concrete samples in a batch reactor setup, removing the sample five times from the experiment for synchrotron X-raying. Noiriel et al. (2009) scanned a limestone sample before, after $9 \mathrm{~h}$, and after $15 \mathrm{~h}$ (end of experiment); for the scans the sample was removed, but remained water-saturated. Noiriel et al. (2005) surveyed limestone dissolution by comparing three scans, taken after subsequent stages of reactive percolation, with the unreacted sample (cores $\varnothing 9 \mathrm{~mm}$, length $21 \mathrm{~mm}$; samples were removed from the cell for the scans).

In each of these studies, the core was removed from its pressure housing prior to scanning so that disturbance of the core during dismantling/remounting for repeated scanning was an issue. This problem can be avoided, if the sample stays mounted for the scan. Likewise, image registration of subsequent scans can be simplified that way. Cur- rently, cell materials with a low X-ray attenuation coefficient that allow the scan of a mounted sample, are deployed to image important hydrodynamic phenomena on the porescale (e.g., two-phase flow in porous media). Since highspeed tomography (even sub-second) has become possible at synchrotron facilities, in situ drainage/imbibition or twophase flow in sample cores have been imaged in real-time (e.g., Myers et al., 2011: air-drainage of water-saturated Bentheim sandstone, core $\varnothing 5 \mathrm{~mm}, 12 \mathrm{~mm}$ length; Berg et al., 2013: imaging of pore-scale displacement events in Berea sandstone in real-time, core $\varnothing 4 \mathrm{~mm}, 10 \mathrm{~mm}$ length; Fusseis et al., 2014, presented an X-ray-transparent cell setup for real-time evolution of pore structure and oil/water imbibition experiments for cylindrical samples of up $\varnothing 3 \mathrm{~mm}$ ). Most recently, X-ray-transparent cell setups were also presented for laboratory-based X-ray micro-computed tomography scanners: Bultheys et al. (2015) performed in situ, timeresolved imaging of dynamic water-rock interaction processes using a PMMA flow cell (drainage of water-saturated Bentheim sandstone by an oil phase: core $\varnothing 6 \mathrm{~mm}, 17 \mathrm{~mm}$ length) to visualize the time-dependant development of preferential flow channels in limestone. Lebedev (2015) reported flooding tests on $\varnothing 5 \mathrm{~mm}$ cores of Bentheim sandstone using a newly developed low-cost cell composed of a PEEK (polyetheretherketone) body and metal nuts and ferrules. Ott et al. (2012) investigated the injection of supercritical $\mathrm{CO}_{2}$ in Berea sandstone (cores $\varnothing 10 \mathrm{~mm}$, length $50 \mathrm{~mm}$ ) and injection of supercritical $\mathrm{H}_{2} \mathrm{~S}$ in limestone (core $\varnothing 125.4 \mathrm{~mm}$, length $90 \mathrm{~mm}$ ), using a layered pressure vessel jacket composed of aluminium and two varieties of Cyanate-Ester. Due to the custom-built setup of $\mu$-CT-scanner and safety cabinet, the core holder design from Ott et al. (2012) permits a maximum sample length of $0.5 \mathrm{~m}$.

Here, we present a new flow-through reaction cell consisting of an X-ray-transparent semicrystalline thermoplastic that has been developed for (long-term) percolation experiments to allow concomitant surveillance of the reaction progress by X-ray microtomography without dismantling the sample. The cell size facilitates its use in standard CT scanner models, while the core size is large enough to permit investigation of intricate reaction textures (e.g., in the course of serpentinization reactions) or complex rock analogues (e.g., to study metasomatic reactions along strong contrasts in chemical potential across different lithologies). The unique material properties of the weakly attenuating, but mechanically strong, cell material allow the experimental examination of rock-fluid interactions under low to moderate temperatures (up to $200^{\circ} \mathrm{C}$ ) and fluid pressures up to ca. $100 \mathrm{bar}$ (10 MPa). The chemical durability of PEEK and the almost complete absence of metals in the design of cell, core holder and flow line facilitate the investigation of chemical systems and reactions where redox control is an issue. 


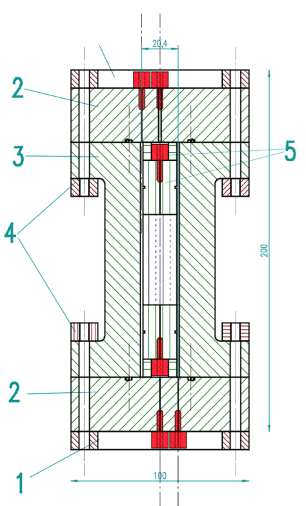

(a)

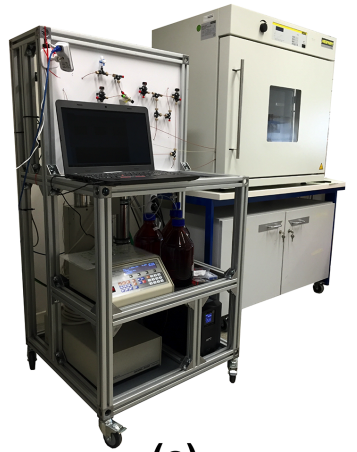

(c)

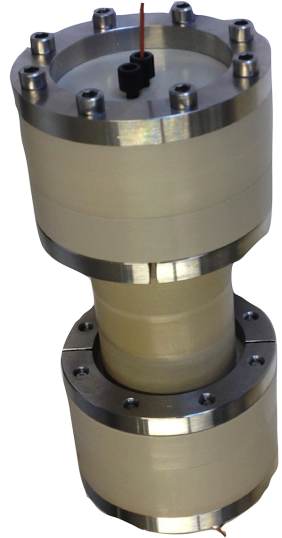

(b)

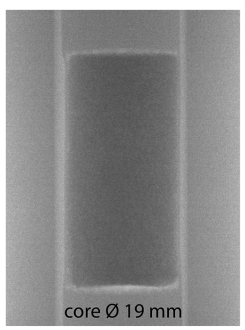

(d)

Figure 1. X-ray-transparent PEEK flow-through reaction cell. (a) Schematic illustration of the percolation cell, the location of the core is indicated. Note: the different parts of the assembled cell are labelled as follows: 1 - steel rings, 2 - end caps, 3 - central part, 4 - steel half-rings, 5 - outlet plug of the core holder and 10-32 finger-tight fitting. (b) Photograph of the assembled cell, with PEEK tubing 1/16" (1.60 mm) O.D. attached. (c) Photograph of an ongoing percolation experiment: the percolation cell is located inside the oven, recharge- and discharge fluids are connected by PEEK capillary tubing. The pump system, recharge- and discharge fluid storage, and the board with the flow line are installed on a mobile rack. To facilitate the transfer of the percolation experiment from the oven laboratory to the X-ray microtomography laboratory for scanning, the mobile rack is equipped with an uninterruptible power supply. (d) $\mu$-CT transmission image of a gypsum core mounted inside the percolation cell.

\section{Materials and methods}

\subsection{PEEK percolation cell}

The semicrystalline thermoplastic material (polyetheretherketone: PEEK) is commercially available (KTK Kunststofftechnik Vertriebs GmbH, Germering, Germany). Since PEEK is machinable, withstands pressure and has a high mechanical strength and hardness over a broad temperature range, an external metal pressure vessel housing is not necessary in the experimental setup. Instead, $20 \mathrm{~mm}$ thick

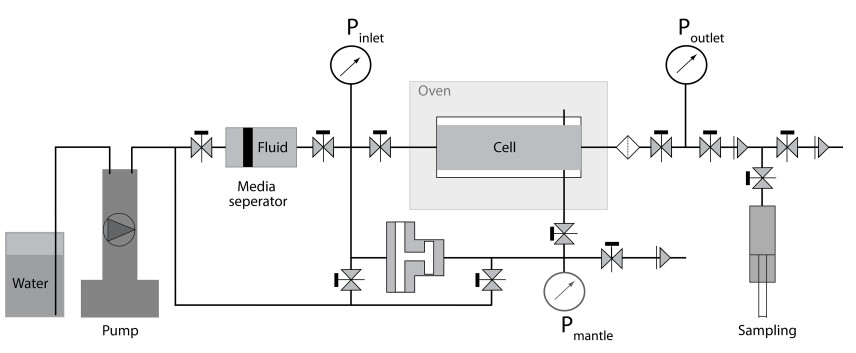

Figure 2. Scheme of the flow line. All tubing, valves etc. are made of PEEK, the pins of the needle valves are made of titanium.

PEEK walls are sufficient to safely maintain pressures up to $100 \mathrm{bar}(10 \mathrm{MPa})$ and temperatures up to $200^{\circ} \mathrm{C}$. We use two PEEK modifications for two different temperature ranges: PEEK extruded natural (density, $\rho: 1.31 \mathrm{~g} \mathrm{~cm}^{3}$; yield stress/tensile strength, $\sigma: 110 \mathrm{MPa}$; heat deflection temperature, HDT: $152^{\circ} \mathrm{C}$ ) up to $120^{\circ} \mathrm{C}$, and PEEK mod extruded ( $\rho: 1.46 \mathrm{~g} \mathrm{~cm}^{3} ; \sigma: 120 \mathrm{MPa}$; HDT: $293^{\circ} \mathrm{C}$ ) up to $200^{\circ} \mathrm{C}$. The percolation cell (Figs. 1 and S1, Supplement) consists of a dumbbell-shaped central part (housing the core holder) and two end caps, which are assembled by screws connecting a set of metallic rings and half-rings (see parts list in Table 1a). The assembled cell measures $210 \mathrm{~mm}$ in height and $100 \mathrm{~mm}$ in diameter. The central part of the dumbbell contains the core holder and is radiographed during the scan (Fig. 1d). It is composed of a hollow cylinder of $22 \mathrm{~mm}$ width with $20 \mathrm{~mm}$ thick walls. Both in- and outlet plugs of the core holder are $19 \mathrm{~mm}$ in diameter and $30 \mathrm{~mm}$ long; they are connected to the PEEK capillary via PEEK 10-32 finger-tight fittings. Where the capillary passes the PEEK cell end caps, the cell is sealed by another finger-tight fitting.

The reaction cell can accommodate rock cylinders of $19 \mathrm{~mm}$ diameter and up to $50 \mathrm{~mm}$ length that are mantled with FEP (fluoroethylene propylene; Adtech Polymer Engineering ltd., Stroud, UK) heat-shrink sleeves. PEEK capillary tubing (Upchurch Scientific, 1/16" O.D. $\times 0.020^{\prime \prime}$ I.D.; $1.60 \mathrm{~mm}$ O.D. $\times 0.5 \mathrm{~mm}$ I.D., see Table S1 in the Supplement) provides fluid circulation through the percolation unit. Spiderweb-type groove patterns on the end-faces of the core holder's inlet and outlet plugs ensure an even distribution of the fluids over the entire face of the core before water enters or leaves the plug. An optional external application of additional mantle pressure (overburden) on the heat-shrink sleeve ensures a well-confined maximum fluid flow through the rock core, even at elevated experimental pressure levels.

The flow-through system (Fig. 1c; schematic flow diagram in Fig. 2) uses two injection pumps (Teledyne Isco D-Series syringe pumps), which can be run either independently of each other or in a synchronized mode. All pumps are of a pulsation-free, positive-displacement pump type and each offers an injection capacity of $500 \mathrm{~cm}^{3}$ in one injection cycle. Fluids discharged from the cell are passed through a backpressure regulator that maintains a constant pressure level 
inside the flow-through apparatus. All parts that are actually in contact with reaction fluids are either made of PEEK (core holder end plugs, capillary), FEP (shrink sleeve) or titanium (tip of needle valves). During the experiment temperature is maintained by a constant-temperature convection oven. Fluid pressures at the inlet and the outlet are controlled by back-pressure regulators (VICI, JR-BPR2, range 20-103 bar). In- and outflow fluid pressures were measured by KELLER ${ }^{\circledR}$ pressure sensors (series 33X, floating piezoresistive transducer, range $0-100 \mathrm{bar}$, material in contact with media: Hastelloy, Viton) and the pressure readings were protocolled by a custom-made Labview ${ }^{\circledR}$ routine. Fluid samples can be retrieved for chemical analyses episodically from the outflow line without disrupting the conditions within the reaction cell: to keep the cell pressure constant during the fluid extraction procedure, the sampling unit is located after a back-pressure valve. This procedure allows the experimentalist to identify the point in time when condition within the cell are at steady-state and compute saturation states with regards to different actual and hypothetical solid reaction products.

During the ongoing percolation experiment, the percolation cell is located inside the oven, and recharge- and discharge fluids are connected by PEEK capillary tubing (Fig. 1c). The pump system, recharge- and discharge fluid storage, and the board with the flow line are installed on a mobile rack. To facilitate the transfer of the percolation experiment from the oven laboratory to the X-ray microtomography laboratory for scanning, the mobile rack is equipped with an uninterruptible power supply.

\subsection{Sample materials}

The following samples have been chosen for initial test runs aimed at demonstrating the unbiased X-ray observations of temporal changes in rock samples mounted in shrink sleeves within the percolation cell. To assess differing states of pore fillings (air vs. fluid), a quartz-dominated sandstone (locality: Gildehaus, Romberg quarry, Germany; formation: Valangin, Lower Cretaceous) has been partially saturated with water. To make a sandstone sample with both water- and airfilled pore spaces, we first flooded the sample completely with water at 50 bar fluid pressure, and then de-pressurized and disconnected the tubing to permit evaporation towards the state we eventually scanned. To demonstrate the sensitivity of in situ cell X-ray observations with respect to subtle differences in mineralogy and delicate textures, we mounted and scanned a mineralogically diverse tertiary sandstone ("Idaho Gray sandstone", Idaho, USA; Idaho formation, tertiary). This sandstone was previously characterized by $\mathrm{M}$. Halisch and S. Kaufhold (personal communication, 2015 ) as coarse grained sandstone with more than $75 \%$ of the grains ranging between 0.35 and $1.1 \mathrm{~mm}$ in size. It consists mostly of quartz $(\sim 80 \%)$ besides heavily weathered muscovite $(\sim 11 \%)$ and K-feldspar $(\sim 4 \%)$. For a grain fraction
$<100 \mu \mathrm{m}$, the mineral proportions identified by M. Halisch and S. Kaufhold (personal communication, 2015) in these investigations revealed less quartz, but higher proportions of feldspar $(\sim 14 \%)$, muscovite $(\sim 6 \%)$ and a high amount of heulandite $(\sim 27 \%)$.

As a test bed for a 4-D study, the conversion of gypsum single crystals (selenite, Morocco; Mineraliengrosshandel Hausen GmbH, Telfs, Austria) to anhydrite has been investigated by concomitant $\mu$-CT monitoring of two percolation experiments over the course of 77 and 35 days. The experimental conditions were $110^{\circ} \mathrm{C}, 45$ bars fluid pressure, and a flow rate of $0.05 \mathrm{~mL} \mathrm{m^{-1 }}$ of a partially gypsumsaturated fluid ( $1.5 \mathrm{~g} \mathrm{~L}^{-1}$ dissolved gypsum; saturation state is $2 \mathrm{~g} \mathrm{~L}^{-1}$ ).

\subsection{X-ray microtomography surveillance}

The X-ray microtomography scans aimed at assessing the applicability of the percolation cell were performed using a CT-ALPHA system (ProCon, Germany) at the Department of Geosciences, University of Bremen, Germany. The sandstone micro-cores mounted in shrink sleeves inside the percolation cell (Fig. 1) were scanned with a beam intensity of $100 \mathrm{kV}$, an energy flux of $300 \mu \mathrm{A}$, and using an aluminium filter in $360^{\circ}$-rotation scans conducted with a step size of $0.225^{\circ}$. The gypsum (selenite) crystals were mounted in a similar fashion and scanned with a beam intensity of $130 \mathrm{kV}$, an energy flux of $350 \mu \mathrm{A}$, and a copper filter, using a $360^{\circ}$ rotation with a step size of $0.3^{\circ}$. Reconstruction of the spatial information on the linear attenuation coefficient in the samples was done with the Fraunhofer software VOLEX, using a GPU-hosted modified Feldkamp algorithm based on filtered backprojection (Feldkamp et al., 1984). Filtering of the raw data, volume reconstruction, segmentation, and rendering were done using Avizo 9.0.1 (FEI).

\section{Results}

Our results demonstrate that the placement of the microcores in the PEEK flow-through cell setup, mounted in shrink sleeves, does not bias the results of X-ray investigation and allows the concomitant surveillance of hydrothermal mineral-fluid interactions by repeated $\mu$-CT scans without dismantling the sample. This assessment is based on data collected for a set of selected samples presented in following sections, which demonstrate the power of the developed experimental setup for facilitating investigations of states and fabrics of water-rock systems undergoing active reaction.

\subsection{Detection of different states of pore filling in the mounted experiment}

The distinction between air-filled and fluid-filled pores of the partially water-saturated quartz-rich Gildehaus sandstone (Fig. 3) is straightforward. Air-filled pores (black in Fig. 3) 

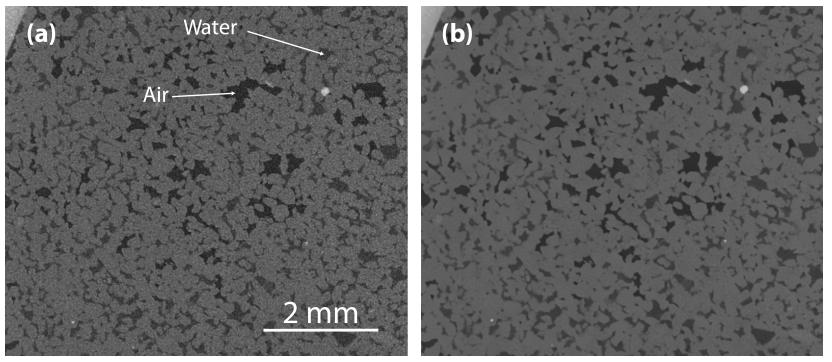

Figure 3. Reconstructed images of a partially saturated, quartz-rich sandstone sample (Gildehaus, Romberg quarry; $\varnothing 19 \mathrm{~mm}$ ) demonstrating the virtually non-existent interference of the PEEK cell setup with distinctive X-ray observations. The samples are scanned inside the assembled cell, surrounded by the PEEK cell material and a shrink sleeve. (a) Unfiltered reconstruction. The distinction between air-filled (black) and fluid-filled (dark grey) pores is already straightforward (voxel size is $8.95 \mu \mathrm{m}$ ). (b) The reconstructed image, treated with a 2-D non-local means filter, allows definite segmentation of the pore fillings. Note the shrink sleeve in the upper left of each image.

can easily be distinguished from fluid-filled pores (dark gray) in the unfiltered image (Fig. 3a, voxel size is $8.95 \mu \mathrm{m}$ ). Filtering of the data set (with non-local means 2-D, Avizo; see Fig. 3b) allows definite segmentation of the different pore fillings and the rock material by means of gray level thresholding.

\section{2 "Region-of-interest" tomography of parts of a mounted sample which exceeds the detector field of view}

The reconstructed images of Idaho Gray sandstone sample $(\varnothing 19 \mathrm{~mm})$, scanned inside the assembled cell, surrounded by the PEEK cell material and a shrink sleeve, clearly show the characteristic X-ray attenuation of the individual phases (Fig. 4). Aiming for an optimal resolution, the field of view for this scan covered approximately half the length of the sample and roughly two thirds of the sample diameter. Delicate fabric elements, such as weathered muscovites and feldspars, can be recognized (voxel size is $6.22 \mu \mathrm{m}$ ) already in the unfiltered reconstructed images (Fig. 4a). Moreover, the recognition of structures, such as filigree zeolite crystals (Fig. 4b and c, both filtered with 3-D Sigma followed by 2-D non-local means) overgrowing weathered muscovite demonstrates the suitability of the cell construction material for high resolution "region-of-interest tomography" (scan and reconstruction of "large" objects exceeding the detector field of view). In this regard, the highest possible magnification will be limited by geometrical issues arising from the percolation cell dimensions and the size of the X-ray $\mu$-CT scanner housing.
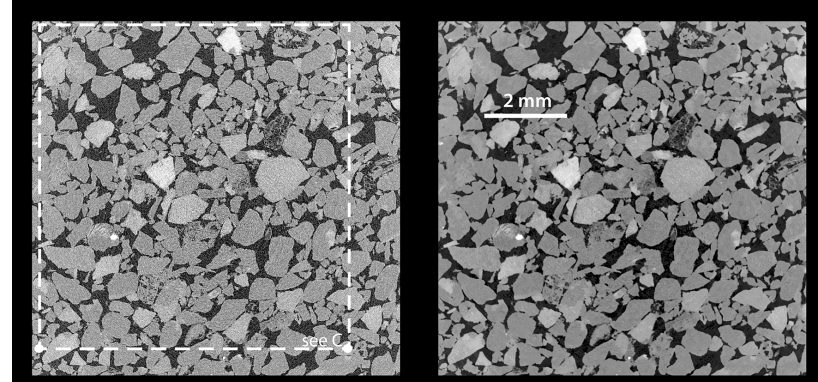

(a)

(b)

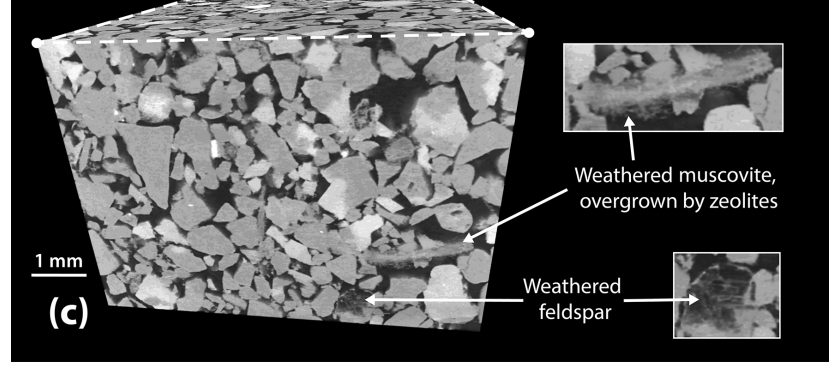

Figure 4. Reconstructed images of a micro-core of Idaho Gray sandstone $(\varnothing 19 \mathrm{~mm})$, scanned inside the assembled cell, surrounded by the PEEK cell material and a shrink sleeve. (a) Unfiltered reconstruction. Delicate fabric elements such as weathered muscovites and feldspars can be recognized (voxel size is $6.22 \mu \mathrm{m}$ ). (b) The filtered image (3-D Sigma followed by 2-D non-local means, both Avizo 9.0.1) of the same slice. (c) 3-D volume reconstruction, with the area defined in (a) being the top layer. The recognition of structures such as filigree zeolite crystals overgrowing weathered muscovite impressively demonstrates the suitability of the cell construction material for "region-of-interest tomography" (scan and reconstruction of "large" objects exceeding the detector field of view).

\subsection{Concomitant $X$-ray surveillance of reaction progress without unmounting or dismantling the sample}

To assess the experimental performance of the flow-through system in terms of the feasibility of repeated, concomitant scans of long-term percolation experiments, we monitored the gypsum/anhydrite transition as a case study of a 4-D fabric evolution. Two percolation experiments were performed (experiment FTGy-A for 77 days and experiment FTGyB for 35 days) using artificially fractured selenite crystals that were subjected to a partially gypsum-saturated fluid $\left(1.5 \mathrm{~g} \mathrm{~L}^{-1}\right)$, percolating at a flow rate of $0.05 \mathrm{~mL} \mathrm{~min}^{-1}$ at $110^{\circ} \mathrm{C}$ and 45 bar $(4.5 \mathrm{MPa})$ fluid pressure. To enhance the formation of flow paths within the selenite micro-core, pure $\mathrm{H}_{2} \mathrm{O}$ was initially used as recharging fluid in the experiment. Figure 4 shows exemplary $\mu$-CT scans of experiment FTGy-A (voxel size is $23.18 \mu \mathrm{m}$ ) that document the reaction progress from (i) the initially fractured micro-core (Fig. 5a), via (ii) the permeability-enhanced stadium after 7 days of percolation of pure $\mathrm{H}_{2} \mathrm{O}$ (Fig. 5b), to (iii) an almost final 


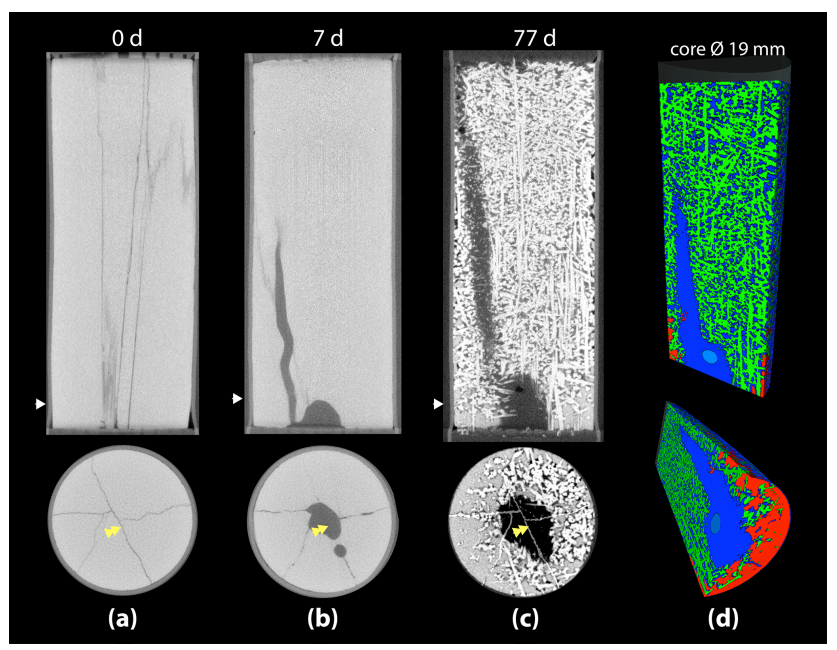

Figure 5. 4-D series of the conversion from gypsum to anhydrite $\left(110^{\circ} \mathrm{C}\right.$, fluid pressure $45 \mathrm{bar}$ (4.5 MPa), direction of flow: upward). In figures (a)-(c) the cross sections are cut at slightly different depths (voxel size is $23.18 \mu \mathrm{m}$ ). (a) Gypsum single crystal (selenite, Morocco), initial state, artificially fractured. (b) Intermediate state, after 7 days percolation of gypsum-undersaturated water (pure $\mathrm{H}_{2} \mathrm{O}$ ) to increase permeability. (c) Late stage of experiment after further 70 days of percolation of a partially gypsum-saturated fluid $\left(1.5 \mathrm{~g} \mathrm{~L}^{-1}\right)$. Gypsum has almost entirely been replaced through the growth of secondary anhydrite needles. (d) 3-D model of segmented pore space, anhydrite and gypsum. Note: (i) white arrowheads in (a)-(c), annotated to the core cross section, mark the position of the single slice shown below; (ii) yellow double arrowheads in (a)(c) mark the position of the initial artificial fracture within the slice.

state with most of the gypsum starting material converted to anhydrite after further 70 days of percolation of the gypsum pre-saturated experimental fluid (Fig. 5c). 3-D-analyses reveal that the conversion of gypsum to anhydrite (see illustration in Fig. 5d) was accompanied by an increase of porosity from 3.6 to $27.7 \mathrm{vol}$. \% from the permeability-enhanced state (ii) (Fig. 5b) to the final state (iii) (Fig. 5c).

By concomitant $\mu$-CT surveillance, a correlation between anhydrite growth and the formation and evolution of flow paths can be documented. In the course of the second percolation experiment FTGy-B (35 days, see Fig. S2), a series of eight $\mu$-CT scans were performed at several time steps (reaching from 0 to 35 days after the beginning of the experiment, as denoted in Fig. S2). The formation and broadening of a main cavity ("worm hole") is clearly visible from the set of successive volume reconstructions. The individual $\mu$-CT slices for each time step reveal the continued growth of anhydrite needles within the selenite. The nuclei of the newly formed anhydrite are located in apparent association with fractures in the selenite (see Fig. S2, stage after 10 days).

A comparison of fabric and mineralogy produced in both selenite percolation experiments provides additional information on the kinetic impact of different cooling rates on the mineralogy of the final run product. While experiment
FTGy-A underwent fast cooling $(<10 \mathrm{~min})$ from oven to room temperature before scanning, run FTGy-B was subjected to a slow cooling process (to room temperature within ca. 60 to $80 \mathrm{~min}$ ) before each scan. The final fabric in both experiments features densely intergrown anhydrite needles separated by fluid-filled intergranular space. The picture obtained after cooling depends on the cooling rate: the newly formed anhydrite is apparently preserved after cooling in the fast-cooling run FTGy-A. In contrast, the slow cooling of run FTGy-B resulted in an extensive secondary conversion of the newly formed anhydrite needles to gypsum.

\section{Conclusions}

The X-ray-transparent reaction cell setup presented in this work holds great potential for fostering the knowledge about the interdependencies between changes in porosity distribution, permeability and their feedback relationship in the course of dissolution and precipitation reactions. $\mu$-CT-based surveillance of percolation experiments can contribute in multiple ways to achieving a more sophisticated understanding of fluid-rock interactions:

1. the consideration of true 3-D spatially resolved $\mu$-CT data of real pore space geometries will facilitate the formulation of relevant pore space models for transport reactions;

2. the identification of preferred growth- or dissolution sites can be correlated to preferential fluid pathways;

3. analysis of changing fluid compositions, changing mineral chemistry and volume proportions, can be used for the parametrization of coupled reaction-transport models;

4. the 4-D evolution of rock fabric and mineralogy, in particular the dissolution or precipitation rate spectra derived from the experiment by $\mu$-CT-based monitoring, can be treated as benchmarks for computer models and can be used for parameterizing such coupled models with increased predictive power.

The results presented in this communication suggest that PEEK as the cell construction material is easily processable, mechanically stable, and generally well-suited for Xray imaging purposes. The straightforward cell design presented here is capable of manifold adaptations to specific experimental requirements in order to mimic a plethora of environmental and geotechnical conditions. 


\section{Information about the Supplement}

The following additional figures and table have been submitted as supplementary material with this manuscript: Figure S1 - Collage of photographs featuring the components of the cell. The labels correspond to the positions in Table S1; Figure S2 - Documentation of formation and evolution of flow paths in the course of gypsum dissolution and anhydrite growth by concomitant $\mu$-CT surveillance (series of eight $\mu$ CT scans); Table S1 - Cell assembly and flow line components, parts list.

\section{The Supplement related to this article is available online at doi:10.5194/se-7-651-2016-supplement.}

Acknowledgements. We are grateful to the people that have contributed to this development: first of all to Georg Nover for his qualified and cordial discussions concerning cell construction details. We thank Norbert Schleifer \& Volker Fendrich and Robert Hinkes \& Volker Feeser for helpful insights into their laboratory materials and methods. We are greatly indebted to Elke Sorgenicht, forewoman of the mechanical workshop, and her staff for their brilliant technical realization. We will remember Matthias Lange and highly value his input on flow path issues and Labview programming. Thanks also go to Martin Kölling and Katja Beier for discussions in the early phase of this project. Matthias Halisch and Stephan Kaufhold are acknowledged for providing both samples and characterizations of Idaho sandstone, Norbert Schleifer is thanked for providing an aliquot of Gildehaus sandstone. We gratefully acknowledge the reviews of G. Nover and H. Steeb.

This study was funded through a grant of the DFG to WB within a Reinhart-Koselleck Project BA 1605/10-1.

The article processing charges for this open-access publication were covered by the University of Bremen.

Edited by: M. Halisch

\section{References}

Andreani, M., Luquot, L., Gouze, P., Godard, M., Hoise, E., and Gibert, B.: Experimental study of carbon sequestration reactions controlled by the percolation of $\mathrm{CO}_{2}$-rich brine through peridotites, Environ. Sci. Technol., 23, 1226-1231, doi:10.1021/es8018429, 2009.

Berg, S., Ott, H., Klapp, S. A., Schwing, A., Neiteler, R., Brussee, N., Makurat, A., Leu, L., Enzmann, F., Schwarz, J.-O., Kersten, M., Irvine, S., and Stampanoni, M.: Real-time 3-D imaging of Haines jumps in porous media flow, P. Natl. Acad. Sci. USA, 110, 3755-3759, doi:10.1073/pnas.1221373110, 2013.

Bultreys, T., Boone, M., Boone, M., De Schryver, T., Masschaele, B., Van Hoorebeke, L., and Cnudde, V.: Fast laboratory-based micro-computed tomography for pore-scale research: illustrative experiments and perspectives on the future, Adv. Water Resour., 1-11, doi:10.1016/j.advwatres.2015.05.012, 2015.

Burlion, N., Bernard, D., and Chen, D.: X-ray microtomography: Application to microstructure analysis of a cementitious material during leaching process, Cement Concrete Res., 36, 346-357, doi:10.1016/j.cemconres.2005.04.008, 2006.

Feldkamp, L. A., Davis, L. D., and Kress, J. W.: Practical conebeam algorithm, J. Opt. Soc. Am. A, 1, 612-619, doi:10.1364/JOSAA.1.000612, 1984.

Fusseis, F., Steeb, H., Xiao, X., Zhu, W.-L., Butler, I. B., Elphick, S., and Mäder, U.: A low-cost X-ray-transparent experimental cell for synchrotron-based X-ray microtomography studies under geological reservoir conditions, J. Synchrotron Radiat., 21, 251253, 2014.

Flukiger, F. and Bernard, D.: A new numerical model for pore scale dissolution of calcite due to $\mathrm{CO}_{2}$ saturated water flow in 3-D realistic geometry: Principles and first results, Chem. Geol., 265, 171-180, doi:10.1016/j.chemgeo.2009.05.004, 2009.

Gouze, P. and Luquot, L.: X-ray microtomography characterization of porosity, permeability and reactive surface changes during dissolution, J. Contam. Hydrol., 120-121, 45-55, doi:10.1016/j.jconhyd.2010.07.004, 2011.

Kühn, M.: Modelling Feedback of Chemical Reactions on Flow Fields in Hydrothermal Systems, Surv. Geophys., 30, 233-251, doi:10.1007/s10712-009-9055-5, 2009.

Lebedev, M.: A low cost pressure cell for micro computer tomography, 3rd International Workshop on Rock Physics, Perth, 13th17 th, 2015.

Myers, G. R., Kingston, A. M., Varslot, T. K., Turner, M. L., and Sheppard, A. P.: Dynamic X-ray micro-tomography for real time imaging of drainage and imbibition processes at the pore scale, International symposium of the society of core analysts, Society of Core Analysts, 2011.

Noiriel, C., Bernard, D., Gouze, P., and Thibault, X.: Hydraulic properties and microgeometry evolution in the course of limestone dissolution by $\mathrm{CO}_{2}$-enriched water, Oil Gas Sci. Technol., 60, 177-192, 2005.

Noiriel, C., Luquot, L., Made, B., Raimbault, L., Gouze, P., and van der Lee, J.: Changes in reactive surface area during limestone dissolution: An experimental and modelling study, Chem. Geol., 265, 160-170, doi:10.1016/j.chemgeo.2009.01.032, 2009.

Noiriel, C., Steefel, C. I., Yang, L., and Ajo-Franklin, J.: Upscaling calcium carbonate precipitation rates from pore to continuum scale, Chem. Geol., 318-319, 60-74, doi:10.1016/j.chemgeo.2012.05.014, 2012.

Øren, P.-E. and Bakke, S.: Reconstruction of Berea sandstone and pore-scale modelling of wettability effects, J. Petrol. Sci. Eng., 39, 177-199, doi:10.1016/S0920-4105(03)00062-7, 2003.

Ott, H., de Kloe, K., van Bakel, M., Vos, F., van Pelt, A., Legerstee, P., Bauer, A., Eide, K., van der Linden, A., Berg, S., and Makurat, A.: Core-flood experiment for transport of reactive fluids in rocks, Rev. Sci. Instrum., 83, 1-6, doi:10.1063/1.4746997, 2012.

Sell, K., Enzmann, F., Kersten, M., and Spangenberg, E.: Microtomographic quantification of hydraulic clay mineral displacement effects during a $\mathrm{CO}_{2}$ sequestration experiment with saline aquifer sandstone, Environ. Sci. Technol., 47, 198-204, doi:10.1021/es3013358, 2013.

Smith, M. M., Sholokhova, Y., Hao, Y., and Carroll, S. A.: $\mathrm{CO}_{2-}$ induced dissolution of low permeability carbonates, Part I: Char- 
acterization and experiments, Adv. Water Resour., 62, 370-387, doi:10.1016/j.advwatres.2013.09.008, 2013a.

Smith, M. M., Sholokhova, Y., Hao, Y., and Carroll, S. A.: Evaporite caprock integrity: An experimental study of reactive mineralogy and pore-scale heterogeneity during brine- $\mathrm{CO}_{2}$ exposure, Environ. Sci. Technol., 47, 262-268, doi:10.1021/es3012723, $2013 \mathrm{~b}$.
Vialle, S., Contraires, S., Zinzsner, B., Clavaud, J. B., Mahiouz, K., Zuddas, P., and Zamora, M.: Percolation of $\mathrm{CO}_{2}$-rich fluids in a limestone sample: Evolution of hydraulic, electrical, chemical, and structural properties, J. Geophys. Res.-Sol. Ea., 119, 2828 2847, doi:10.1002/2013jb010656, 2014. 